\title{
Enzyme-Histochemical Visualization of Lymphatic Capillaries in the Mouse Tongue: Light and Electron Microscopic Study
}

\author{
By
}

\section{Seiji KATO and Ryosuke MIYAUCHI}

\author{
Department of Anatomy, Medical College of Oita, \\ Oita, Japan
}

- Received for Publication November 12, 1988-

\begin{abstract}
Key words: Lymphatic vessels, Tongue, 5'-Nucleotidase, Alkaline phosphatase, Histochemistry, Electron microscopy
\end{abstract}

\begin{abstract}
Summary: The distinction between lymphatic capillaries and blood capillaries in the mouse tongue was studied enzyme-histochemically by light and electron microscopy. The lymphatic walls are characterized by a strong 5 '-nucleotidase (5'-Nase) activity, whereas those of the blood capillaries reveal a significantly lower or no activity. The alkaline phosphatase (ALPase) activity, on the other hand, is markedly higher in the blood capillaries than in the lymphatic capillaries. The specific reaction of 5'-Nase activity in the lymphatic capillaries is obtained by simultaneous inhibition of ALPase on incubation in a medium (Wachstein and Meisel, 1957) with L-tetramisole for 5'-Nase histochemistry. The distribution and intensity of the 5'-Nase activity in the lymphatic capillaries can be adequately visualized by comparison with serial cryostat sections for histochemical detection under light and backscattered imaging scanning electron microscopes. The reaction products of the 5'-Nase activity are localized on the outer surface of the cell membrane of the lymphatic endothelial cells, whereas those in the blood capillaries reveal a weak or no reaction. The present results demonstrates satisfactory isolated visualizations of $5^{\prime}$-Nase activity in the lymphatic capillaries and of ALPase activity in the blood capillaries.
\end{abstract}

In the past, many investigators have employed a variety of methods such as parenchymal or vascular injection of colored materials and impregnation with silver nitrate to demonstrate the structure of the lymphatic vessels in various organs. However, sufficient differentiation of the lymphatic vessels, particularly lymphatic capillaries, from blood vessels or from space in the connective tissue, is generally difficult in ordinary stained sections. The information on the fine structural features of lymphatic endothelium has been enriched by the findings of transmission electron microscopy (Casley-Smith, 1977; Albertine and O'Morchoe, 1980; Courtice, 1980; Leak, 1980). Furthermore, in the last decade, the surface morphology of the initial lymphatics has been demonstrated in the rat tongue by scanning electron microscopy (Castenholz, 1984, 1985, 1987).

Early histochemical studies on the wall of lymphatic vessels were described by Pinto $e t$ al. (1957). The histochemical characteristics concerning the presence of elastic fibers Send offprint requests to: Dr. Seiji Kato, Department of Anatomy, Medical College of Oita, Oita 879-56, Japan 
around the vessels were revised over subsequent years (Pfleger, 1964; Nishiyama, 1967; Ohkuma, 1975). Based on enzyme-histochemical observations, Nishida and Ohkuma (1984) and Ohkuma and Nishida (1987) have demonstrated that blood capillaries reveal a higher activity of certain enzymes, such as alkaline phosphatase, aminopeptidase, peroxidase and acid p-nitrophenyl phosphatase, than do lymphatic capillaries. Vetter (1970) and Heusermann (1979, quoted by Werner $e t$ al.) found that the endothelium as well the media of lymphatic vessels is characterized by a strong 5'-nucleotidase (5'-Nase) activity, whereas blood vessels reveal significantly lower or no activity, and that alkaline phosphatase (ALPase), on the other hand, although missing in the lymphatic vessels, is positive in most of the blood vessels. Borgers (1973) reported L-tetramisole to be an inhibitor of ALPase, so that the 5'-Nase reaction can be carried out specifically, since Ltetramisole exerts no influence on the 5'-Nase activity (DePierre and Karnovsky, 1974). Recently, Werner et al. (1987) indicated that isolated visualization of 5'-Nase activity with simultaneous inhibition of ALPase by Ltetramisole can be considered to represent the best way of demonstrating lymphatic capillaries enzyme-histochemically, based on their light microscopic observations of the rat pharynx.

In the present study, two sets of adjacent serial frozen sections of the mouse tongue were used to investigate the 5'-Nase activity in the lymphatic capillaries by light and backscattered imaging scanning electron microscopy, respectively. In addition, enzymehistochemical evaluation of blood capillaries was carried out by ALPase histochemistry. The results provide further information on the three-dimensional features and fine structure in support of a concept for the enzymehistochemical differentiation of the small lymphatics from the blood capillaries.

\section{Materials and Methods}

\section{Experimental animals}

The tongues of 40 adult male BALB/c mice were examined. Mice anesthetized with ether were perfused via the aorta as reported previously (Kato and Schoefl, 1988). The perfusion was started by hand with $5 \mathrm{ml}$ of cold $0.1 \mathrm{M}$ cacodylate buffer $(\mathrm{pH}$ 7.2) containing $7 \%$ sucrose. This was followed by ice-cold formaldehyde- $\mathrm{CaCl}_{2}$ fixative $(6 \%$ paraformaldehyde, $1 \% \mathrm{CaCl}_{2}$ ) in $0.1 \mathrm{M}$ cacodylate buffer (7\% sucrose) for enzymehistochemistry or $2.5 \%$ glutaraldehyde in 0.1 $M$ cacodylate buffer for light and scanning electron microscopy.

\section{Histochemistry}

Light microscopy: After perfusion, the tongue was excised and frozen at a temperature of $-20^{\circ} \mathrm{C}$. Frozen sections of 10 $\mu \mathrm{m}$ or $20 \mu \mathrm{m}$ in thickness were cut in a cryostat (Sakura Coldtome CM-41, Sakura Seiki, Tokyo) and mounted on albumin coated slides or cover glasses. Air-dried sections were fixed in the same fixative for a further $10 \mathrm{~min}$. These sections were washed in three changes of $0.1 \mathrm{M}$ cacodylate buffer and then incubated for $30-60 \mathrm{~min}$ at $37^{\circ} \mathrm{C}$ in the standard medium for $5^{\prime}$-Nase activity according to the method of Wachstein and Meisel (1957). This medium contains: $0.2 \mathrm{M}$ Tris-maleate buffer ( $\mathrm{pH} 7.2$ ), $20 \mathrm{ml}$; 5'-adenosine monophosphate ( $\mathrm{Na}$ salt; AMP), $25 \mathrm{mg}$; $0.1 \mathrm{M} \mathrm{MgSO}_{4}, 5 \mathrm{ml}$; sucrose, $3-4 \mathrm{~g}$; distilled water, $22 \mathrm{ml}$; and $2 \%$ $\mathrm{Pb}\left(\mathrm{NO}_{3}\right)_{2} 3 \mathrm{ml}$. To obtain the specific reaction for 5'-Nase activity, $12 \mathrm{mg}$ of Ltetramisole $(1 \mathrm{mM})$ as an inhibitor of ALPase was added to the medium. When demonstration of 5'-Nase activity was followed by the ALPase reaction, the incubation mixture did not contain L-tetramisole. Following incubation in the medium, the sections for light microscopy were rinsed in distilled water and then immersed in $1 \%$ yellow ammonium 
sulfide for $2 \mathrm{~min}$ for visualization.

Histochemical visualization of ALPase was achieved for 20-60 min at room temperature according to the azo-dye method (Burstone, 1962): $40 \mathrm{mg}$ of naphthol AS-MX phosphate disodium salt (Sigma) was dissolved in $2 \mathrm{ml}$ of N,N'-dimethyl-formamide and added to 40 $\mathrm{ml}$ of $0.1 \mathrm{M}$ Tris-HCL buffer ( $\mathrm{pH}$ 9.2) containing $40 \mathrm{mg}$ of fast blue BB (Sigma). The sections were thoroughly rinsed in distilled water and mounted with glycerin for light microscopy.

In the control studies, sections were incubated in a substrate-free medium. For specific inhibition of the 5'-Nase activity, sections were treated with $\mathrm{NiCl}_{2}(50 \mathrm{mM})$ in distilled water for $10 \mathrm{~min}$ before being incubated in the reaction medium.

Scanning electron microscopy (backscattered electron imaging): After incubation in the medium with L-tetramisole for examining the 5'-Nase activity, the sections, which were just adjacent to each section for light microscopy were gently rinsed in $0.1 \mathrm{M}$ cacodylate buffer. These specimens were dehydrated in ascending concentrations of ethanol, transferred to t-butylalcohol $(1-2 \mathrm{ml}$; three changes) and then dried according to the t-butylalcohol freeze-drying method of Inoue and Osatake (1988). Dried specimens were mounted on an aluminum stub with carbon paste. The specimens were uniformly coated with carbon by evaporation to a thickness of about $20 \mathrm{~nm}$ for the purpose of preventing electron charging artefacts.

The specimens were examined under a JEOL JSM-820 SEM equipped with a high density annular semiconducting pair detector (diode type). Micrographs of backscattered electron imaging (BEI) were taken under accelerating voltages in the range of $15-20 \mathrm{KV}$, and those of secondary emission imaging (SEI) at 10,15 or $20 \mathrm{KV}$. For many BEI observations, a reduced working distance of approximately $8 \mathrm{~mm}$, a beam spot size of $250 \AA$, and a specimen stage tilt of $0^{\circ}$ were employed in the present study.

Transmission electron microscopy (TEM): After perfusion fixation, the tongue was excised and sliced. The tissue slices were immersed in the same fixative for a further 30 $\mathrm{min}$, and then rinsed in the $0.1 \mathrm{M}$ cacodylate buffer (pH 7.2) containing 7\% sucrose. The specimens were incubated in the reaction medium with $\mathrm{L}$-tetramisole for examining the 5'-Nase activity for $30 \mathrm{~min}$ at $37^{\circ} \mathrm{C}$ and then postfixed in $2 \%$ osmium tetroxide in $0.1 \mathrm{M}$ cacodylate buffer $\left(\mathrm{pH} \mathrm{7.2)}\right.$ for $1 \mathrm{hr}$ at $4^{\circ} \mathrm{C}$. These specimens were dehydrated in ascending concentrations of ethanol and embedded in Spurr's resin (Taab). Ultrathin sections were cut with glass or diamond knives on a Reichert $\mathrm{OmU}_{4}$ ultramicrotome. Semithin sections for light microscopy were stained with $1 \%$ toluidine blue. These materials were examined under a JEM 300C TEM.

\section{Light and scanning electron microscopy}

Animals were perfused and fixed as described in the preceding section. The tongue was then excised, and cut into small blocks, or sliced with a razor blade. These specimens were immersed in the same fixative. Sections of $10 \mu \mathrm{m}$ in thickness for light microscopy were stained with $1 \%$ toluidine blue. The adjacent sections of $20 \mu \mathrm{m}$ in thickness were further prepared for examination of their surface morphology by SEM. These sections were dehydrated, dried according to the $\mathrm{t}$ butylalcohol freeze-drying method, coated with gold $(20 \mathrm{~nm})$, and then examined under a JSM 820 or 25 S SEM.

\section{Results}

\section{Light microscopy}

Histochemical demonstration of 5'-Nase activity was particularly successful after incubation with the medium containing Ltetramisole as an inhibitor of ALPase. Strong 
reaction product of 5'-Nase was observed in the lymphatic vessels in the subepithelial layer and among the muscle bundles, whereas significantly lower or no activity was detected in the blood capillaries (Fig. 1). The lymphatic capillaries were found to have peculiar contours, and their endothelial cells were bordered by a wavy outline (Fig. 2). The brown coloration due to lead sulfide ranged from a light shade to dark tones during the process of incubation. In preparations using such a medium with L-tetramisole, no changes in localization and intensity of the reaction product were revealed in the lymphatic capillaries (Figs. 1 and 2) as compared to the case of the medium without L-tetramisole (Fig. 3).

When the incubation medium for the 5'Nase activity did not contain L-tetramisole (Fig. 3), the sections were further incubated in the medium for ALPase activity (Fig. 4).

The ALPase activity in the blood capillaries was visualized as a blue reaction product, which contrasted noticeably with the dark brown reaction product of the 5'-Nase activity in the lymphatic capillaries (Figs. 4, 5 and 6). Figures 4 and 5 further show the distribution of 5'-Nase positive lymphatic capillaries and ALPase positive blood capillaries in the subepithelial layer and among the muscle bundles. On increasing the incubation time from 20 to $60 \mathrm{~min}$, most of the blood capillaries revealed a positive ALPase activity in contrast to the results for a shorter incubation time. Such a reaction pattern of ALPase did not change, regardless of whether the section was previously submitted to the 5'-Nase assay or not.

\section{Secondary or backscattered electron imaging (SEI, BEI)}

The secondary emission images showed the surface structure of sectioned specimens (Figs. 7, 9 and 11) which were adjacent to the section used for light microscopy (Fig. 1). These SEM photographs revealed, to some extent, the three-dimensional structure of the lymphatics and blood capillaries in the subepithelial layer or among the muscle bundles, although there was a certain degree of damage to the surface morphology, probably due to the tissue preparation procedures, especially the cryostat sectioning. Of course, samples prepared for BEI histochemistry and coated only with carbon frequently displayed charging artefacts under a high accelerating voltage. The BEI of the same area, however, as in the SEI, clearly visualized the reaction product of the 5'-Nase activity in the lymphatic wall, as highlights of positive reaction, due to the high atomic number of lead $(\mathrm{Z}=82)$ (Figs. 8, 10 and 12). These images may correspond to the brown or black coloration as reaction products of 5'-Nase activity on the light micrographs of the adjacent sections (Fig. 1).

A well developed subepithelial lymphatic plexus could be demonstrated in the tongue by light and scanning electron microscopy (Figs. 13, 14 and 15). All vessels in the vascular area were furnished with a layer of endothelial cells. The lumen of the lymphatic vessels also appeared to be empty. The luminal surface of these lymphatic vessels exhibited quite an irregular profile, which had wavy borders with numerous overlaps forming "pockets" (Fig. $15)$. Some of the short processes of the endothelial cells did not touch the cell surface and were inserted with a broad flap near the cellular border (Fig. 15). The cellular perikarya protruded slightly into the lumen.

\section{Transmission electron microscopy (TEM)}

When using TEM, the reaction products of the 5'-Nase activity could be localized on the cell surfaces of the lymphatic endothelium in the subepithelial layer (Fig. 16) and among the muscle bundles (Fig. 17). Dense granular precipitates of the reaction product were found in connection with the outer surface of 
the cell membrane (Fig. 18). Fine precipitates were partly observed on the endothelial cell surface at the basal side (Fig. 18). On the other hand, such reaction products of 5'-Nase activity were not detected in the blood capillaries (Fig. 17). Control reactions, which were performed in the incubation medium without substrate or treated with $\mathrm{NiCl}_{2}$ before being incubated in the reaction medium, did not reveal any precipitation.

\section{Discussion}

The present results demonstrate that 5'Nase activity with simultaneous inhibition of ALPase by L-tetramisole can be considered histochemically suitable for the identification of lymphatic capillaries by light and electron microscopy, and that the histochemical reaction product can also be identified in backscattered electron imaging of SEM. Furthermore, the isolated visualization of 5'-Nase activity and ALPase activity on the same section provides a satisfactory differentiation of the lymphatics from the blood capillaries.

5'-Nase, an important enzyme in the metabolism of nucleotides, has widely been employed as a marker enzyme of cell membranes (Song and Bodansky, 1967; DePierre and Karnovsky, 1973). A histochemical technique for the detection of 5'-Nase activity by light and electron microscopy was developed by Gomori (1939), and subsequently improved by Wachstein and Meisel (1957). With the present method, the phosphate liberated during the 5'-Nase reaction is precipitated as lead phosphate and can then be detected as black lead sulfide after immersing the material in ammonium sulfide solution under the light microscope (Pearse, 1968). Since the yield of backscattered electrons is strongly dependent on the average atomic number $(\mathrm{Z})$ of the specimen; cellular components stained with a heavy metal (lead) can be visualized by SEM equipped with a backscattered electron detector. This histochemical method is therefore considered useful for the comparative visualization of lymphatic vessels under the light and scanning electron microscope.

The visualization of the 5'-Nase activity depends on the presence of the substrate AMP in the incubation medium. Since nonspecific ALPase also metabolizes AMP besides 5'Nase (Reis, 1951), ALPase activity will also be found in the blood capillaries and the lymphatics. Thus, to obtain the specific reaction of the 5'-Nase activity, complete inhibition of ALPase is required. L-tetramisole as an inhibitor of ALPase is considered to be effective for the specific reaction of 5'-Nase because it exerts no influence on the 5'-Nase activity (DePierre and Karnovsky, 1974). However, previous studies on the histochemical differentiation of small lymphatics from blood capillaries have not utilized Ltetramisole (Vetter 1970; Heusermann, 1979). For this reason and for convenience in effecting the isolated visualization of the enzyme in lymphatic vessels, Werner et al. (1987) first demonstrated a strong activity of 5'-Nase, on inhibiting the ALPase activity with L-tetramisole, in the lymphatic wall of the rat pharynx at the light microscopic level. Our light micrographs of enzyme-histochemical preparations of lymphatic vessels, as demonstrated in Figures 1-6, closely resemble those presented previously by Werner et al. (1987). The present electron microscopic studies further revealed that the 5'-Nase activity is localized on the cell surface of the lymphatic endothelial cells at the luminal surface, as well as at the basal side.

One of the authors (Kato, 1988) recently found that lymphatic endothelial cells exhibit an irregular pattern of serrate borders at the cellular edges in the mouse thymus. Such charácteristics of the luminal surface morphology of the lymphatics are also seen in the mouse tongue and they are quite similar to 
those in the rat tongue as reported previously by Castenholz (1984, 1985, 1987). Lymphatic endothelial cells may display highly specialized surface features in their differentiation from blood capillary endothelial cells. In the present study, furthermore, the strong reaction products of 5'-Nase activity on the lymphatic wall could be demonstrated three-dimensionally by comparing the SEI and BEI, and may correspond to the coloration seen in light micrographs. Thus, by combining observations of the surface structure and histochemical characteristics, a more accurate identification of lymphatics and blood vessels should become possible.

\section{Acknowledgments}

The authors are grateful to Prof. Dr. I. Nakayama, Department of Pathology, Medical College of Oita, for his kind support during this study. Thanks are also due to $\mathrm{Mr}$. T. Negishi of the Application Research Center, JEOL Co. Tokyo, for his technical assistance in the backscattered electron imaging of SEM. This study was supported in part by a research grant (No. 63304029, Prof. Dr. S. Uchino) from the Ministry of Education, Science and Culture of Japan.

\section{References}

1) Albertine, K.H. and O'Morchoe, C.C.C.: Renal lymphatic ultrastructure and trans-lymphatic transport. Microvasc. Res., 338-351, 1980.

2) Borgers, M.: The cytochemical application of new potent inhibitors of alkaline phosphatases. J. Histochem. Cytochem., 21: 812-824, 1973.

3) Burstone, M.S. (ed).: Enzyme histochemistry. Academic Press, New York, 1962.

4) Casley-Smith, J.R.: Lymph and lymphatics. In: Haley, G. and Burton M.K. (eds.). Microcirculation. University Park Press, Baltimore, London/ Tokyo, Vol. I, P. 403-502, 1977.

5) Castenholz, A.: Morphological characteristics of initial lymphatics in the tongue as shown by scanning electron microscopy. Scanning Electron
Microsc., III: 1343-1352, 1984.

6) Castenholz, A.: The endothelium of initial lymphatics during postnatal development of the rat tongue. Scanning Electron Microsc., III: 1201-1208, 1985.

7) Castenholz, A.: Structural and functional properties of initial lymphatics in the rat tongue: Scanning electron microscopic findings. Lymphology, 20: 112-125, 1987.

8) Courtice, F.C.: The lymphatics circulation. In: Schwartz, C.J., Werthessen, N.T. and Wolf, S. (eds.) Structure and function of the circulation. Plenum Press, New York, Vol. 2, P. 487-602, 1980.

9) DePierre, J.W. and Karnovsky, M.L.: Ectoenzyme of granulocytes: 5'-Nucleotidase. Science, 184: 1096-1098, 1974.

10) Gomori, G.: Microtechnical demonstration of phosphatase in tissue section. Proc. Soc. Exp. Biol. Med., 42: 23-26, 1939.

11) Heusermann, U.: Morphologie der Lymphgefä $\beta$ e, der Nerven, der Kapsel und der Trabekel der menschlichen. Milz. Habilschr. Med. Fakultät, Kiel, 1979 (quoted from Werner et al., 1987).

12) Inoue, $T$. and Osatake, H.: A new drying method of biological specimens for scanning electron microscopy: The t-butyl alcohol freezedrying method. Arch Histol. Cytol., 51: 53-59, 1988.

13) Kato, S.: Intralobular lymphatic vessels and their relationship to blood vessels in the mouse thymus: Light- and electron microscopic study. Cell Tissue Res., 253, 181-187, 1988.

14) Kato, S. and Schoefl, G.I.: The microvasculature of the normal and involuted mouse thymus: Light and electron microscopic study. Acta Anat., 1988 (in press).

15) Leak, L.V.: Lymphatic vessels. In: Johannessen, J.V. (ed). Electron microscopy in human medicine. McGraw-Hill, New York, Vol. 5, P. 155-212, 1980.

16) Nishida, S. and Ohkuma, M.: Enzyme-histochemical differentiation of the human cutaneous lymphatic from the blood capillary. Immunol. Hematol. Res., 2: 108-112, 1984.

17) Nishiyama, S.: Lymphatic vessels in the cutaneous biopsy specimens. Hifuka no Rinsho, 12: 905-912, 1967 (in Japanese).

18) Ohkuma, M.: Histochemical and electron microscopic studies of the human cutaneous lymphatic capillary. Tohoku J. Exp. Med., 115, 121-128, 1975.

19) Ohkuma, M. and Nishida, S.: Enzyme- 
histochemical differences between the lymphatic and blood capillary. Microvasculation, 1: 285-286, 1987.

20) Pearse, A.G.E. (ed.): Histochemistry: Theoretical and applied. 3rd Ed., Churchill Livingston, London, 1968.

21) Pfleger, L.: Histologie und Histopathologie cutaner Lymphgefä $\beta$ e der unterner Extremitäten. Arch. Klin. Exp. Derm., 221: 1-22, 1964.

22) Pinto, S., Coimbra, A. and Castro-Correia, J.: Études sur l'anatomo-physiologie du système lymphatique. V. Sur l'histochimie des vaisseaux et des ganglions lymphatiques chez le chien. C. R. Assoc. Anat., 43: 776-782, 1957.

23) Reis, J.L.: The specificity of phosphomonoesterases in human tissues. Biochem. J., 48: $548-551,1951$.
24) Song, C.S. and Bondansky, O.: Subcellular localization and properties of 5'-nucleotidase in the rat liver. J. Biol. Chem., 242: 694-699, 1967.

25) Vetter, W.: Alkalische Phosphatasen in Mastzellen, Blut- und Lymphgefä $\beta$ e der Rattenzunge: 5'-Nucleotidase-, unspezifische alkalische Phosphatase- und Polyphosphatase(ATP'ase) Aktivität unter besonderer Berücksichtigung des pH. Z. Anat. Entwickl.-Gesch., 130: 153-176, 1970.

26) Wachstein, M. and Meisel, E.: Histochemistry of hepatic phosphatases at a physiologic $\mathrm{pH}$. Amer. J. Clin. Pathol., 130: 153-176, 1957.

27) Werner, J.A., Schünke, M. and Tillmann, B.: Histochemical visualization of lymphatic capillaries in the rat: A comparison of methods demonstrated at the posterior pharyngeal surface. Arch Histol. Jap., 50: 505-514, 1987. 


\section{Explanations of Figures}

\section{Plate I}

Figs. 1-6. Light micrographs of cryostat sections of mouse tongues showing lymphatic vessels and blood vessels for histochemical visualization. 1, 2 5'-Nase activity of tissues incubated in the medium with L-tetramisole. Dark brown or black coloration indicates distinctly positive reactions for 5'-Nase activity in the lymphatic capillaries in the subepithelial layer and among the muscle bundles. Blood capillaries reveal significantly lower or no activity. Note the peculiar contours of the endothelial cells of the lymphatic wall. $\times 150$, $\times 450.35$ '-Nase activity of tissue incubated in the medium without L-tetramisole. $\times 120.45^{\prime}$-Nase and ALPase activity of the same section as shown in Figure 3, incubated in the medium for 5'-Nase activity followed by ALPase assay. Note that the blood capillaries reveal an ALPase reaction (blue) in contrast to the 5'-Nase reaction (dark brown). $\times 120.5$ 5'-Nase and ALPase activity of lymphatic vessels and blood vessels in another specimen incubated in the medium without L-tetramisole. $\times 150$. 6 Further magnification of the lymphatic and blood capillaries shown in Figure 5. Note the isolated visualization of 5'-Nase positive lymphatic capillaries (dark brown) and ALPase positive blood capillaries (blue). $\times 370$. 
Enzyme Histochemistry of Lymphatic Vessels

Plate I

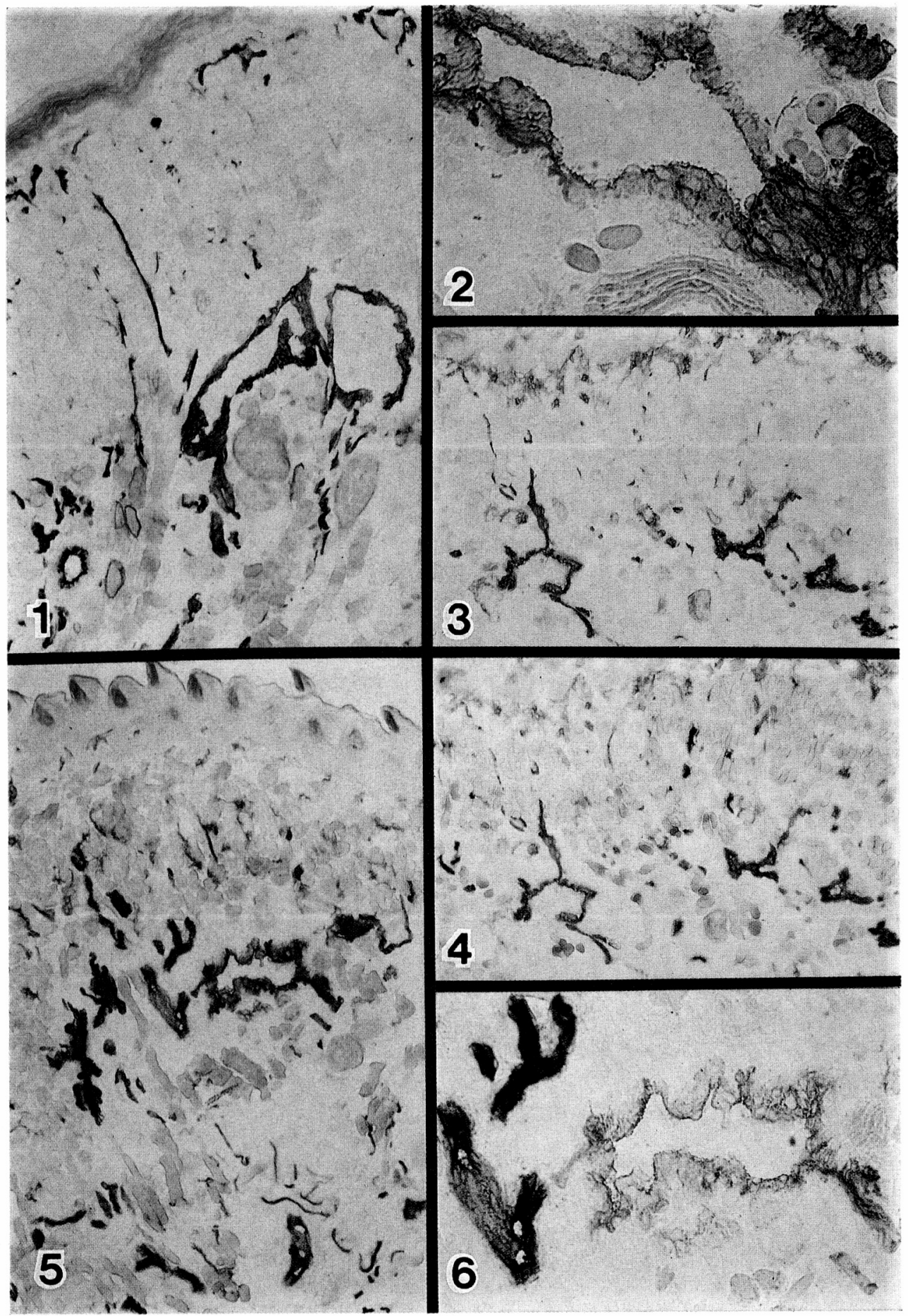




\section{Plate II}

Figs. 7-12. Secondary and backscattered electron imaging SEM micrographs of the serial cryostat section adjacent to that shown in Figure 1. 7, 9, 11 Secondary electron imaging (SEI), 8, 10, 12 Backscattered electron imaging (BEI) with highlights of 5'-Nase reaction products. 9-12 Further magnifications of Figures 7 and 8 , respectively. 7, $8 \times 70 ; 9-12 \times 350$. 
Plate II
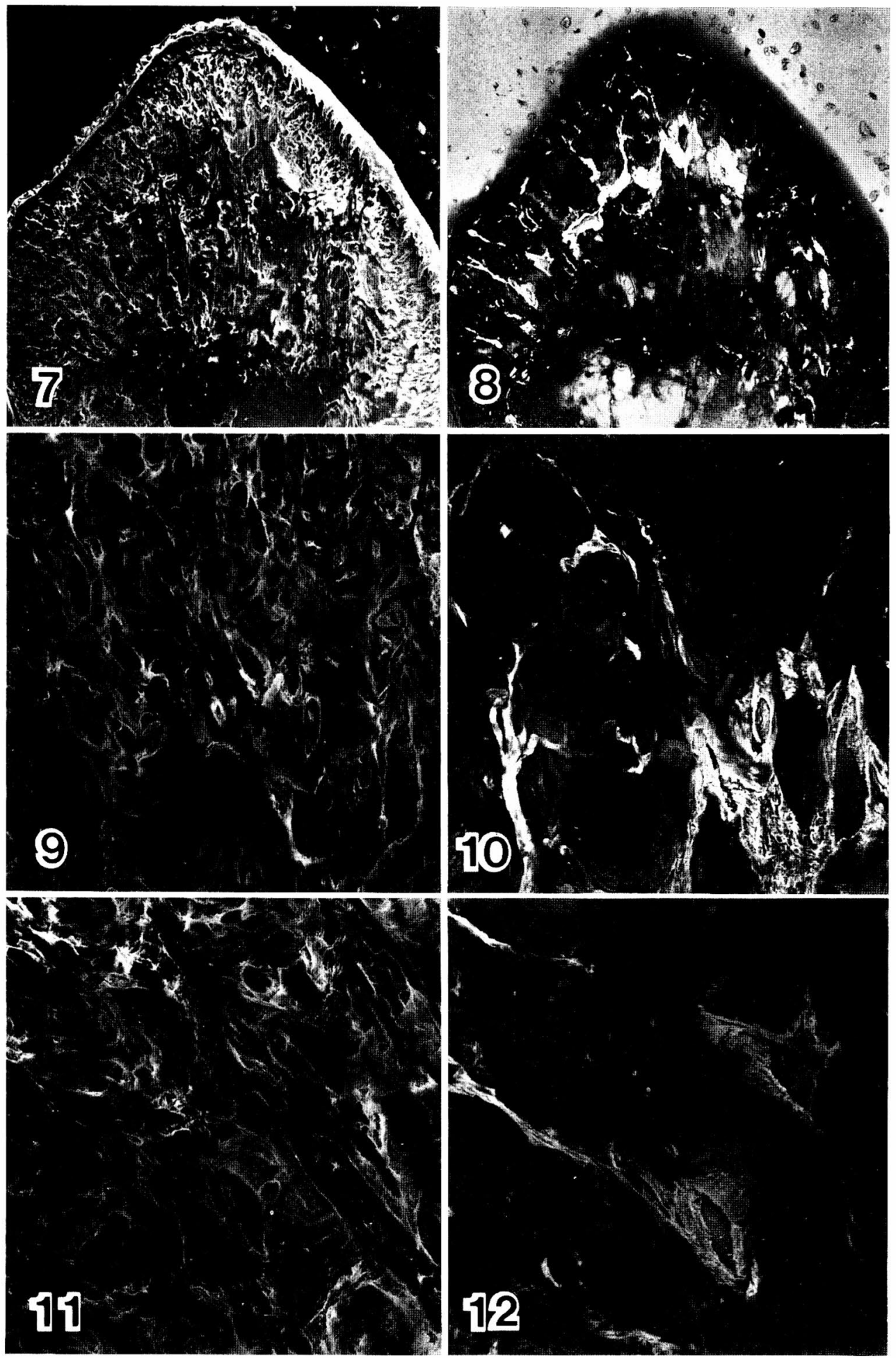


\section{Plate III}

Fig. 13. Light micrograph of a paraffin tissue section stained with $1 \%$ toluidine blue. Some subepithelial lymphatic vessels (LV) forming a plexus and blood capillaries (arrows) are present. $\times 95$.

Fig. 14. SEM view of subepithelial lymphatic vessels (LV) and blood vessels (arrows) in the serial section adjacent to that shown in Figure 13. $\times 90$.

Fig. 15. Further magnification of the luminal surface of lymphatic vessel (LV) indicated by the arrowhead in Figure 14. Note the wavy borders with numerous overlaps (pockets) and endothelial cell processes (arrowheads). $\times 1500$.

Fig. 16-18. TEM views of 5'-Nase positive lymphatic capillaries in the subepithelial layer (16) and among the muscle bundles (17). 16, $17 \times 6700$. Note the 5'-Nase positive lymphatic vessel (LV) and the 5'-Nase negative blood vessel (BV). 18 Further magnification of the 5'-Nase-positive lymphatic capillary shown in Figure 17. Dense granular precipitates are seen in the outer surface (arrows) of the cell membrane and also in the area (arrowheads) at the basal side. $\times 15,000$. 

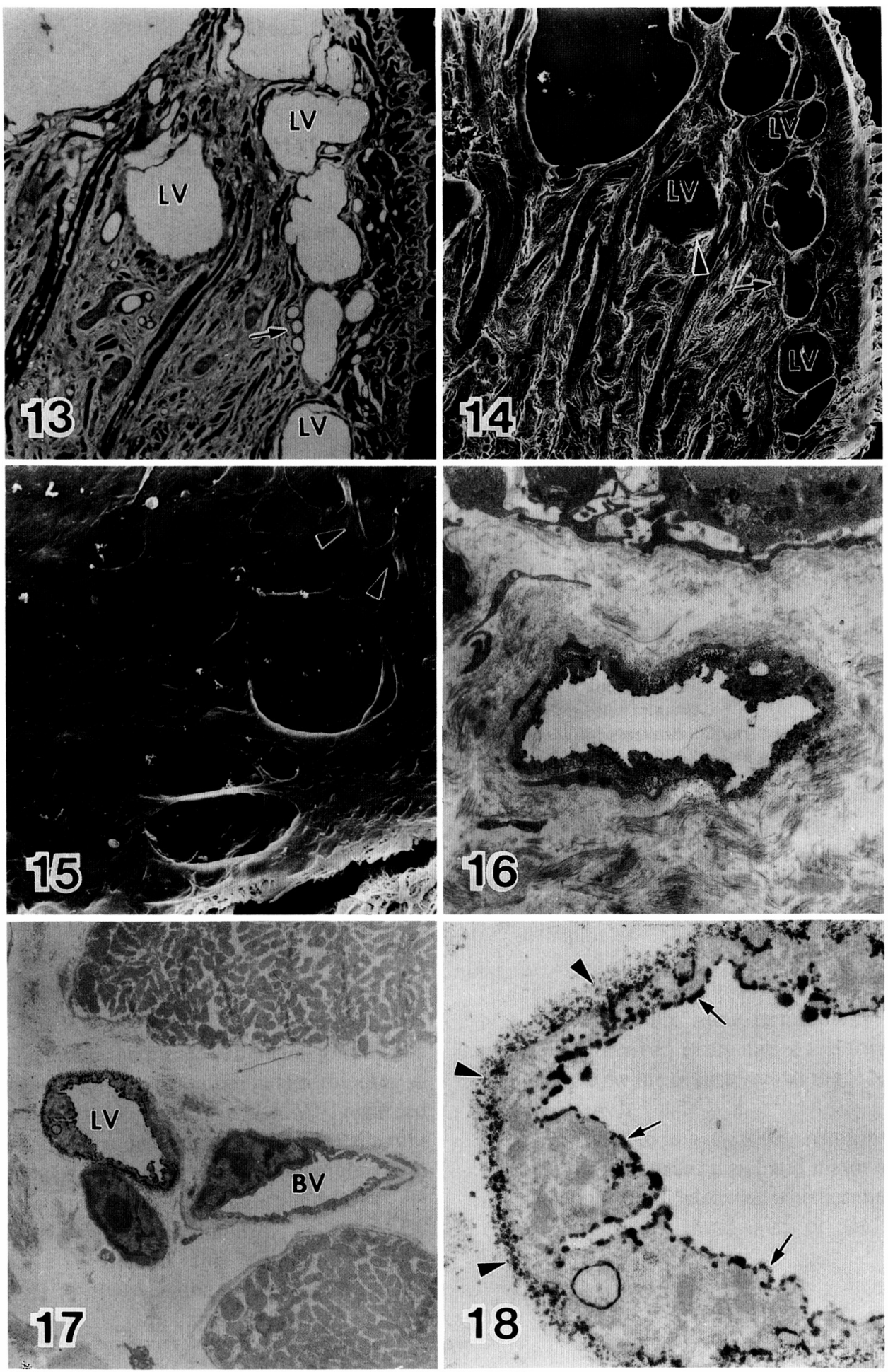